\title{
Proceeding
}

Supplementary Issue: Summer Conferences of Sports Science. Costa Blanca Sports Science Events, 25-26 September 2020. Alicante, Spain.

\section{Physical activities and enjoyment during the lockdown: Effect of home-based supervised training among children and adolescents}

\author{
VALERIO BONAVOLONTÀ, STEFANIA CATALDI 1 , DAVIDE MACI, FRANCESCO FISCHETTI \\ School of Medicine, Department of Basic Medical Sciences, Neuroscience and Sense Organs, University of \\ Study of Bari "Aldo Moro", Bari, Italy
}

\begin{abstract}
Enjoyment during physical and sport activities is an essential and well recognized component that has been also related to motor ability in children. During the period of home confinement due to Covid-19 lockdown, the Italian version of the Physical Activity Enjoyment Scale (PACES-It) was used to evaluate the level of enjoyment in physical and sports activities. The beginning stem of the questionnaire was modified by asking subjects "During the lockdown, when I am physically active...". Data were collected on a sample of 140 among children and adolescents (60 aged $6-11$ and 80 aged $12-15,66 \%$ males and $34 \%$ females). About $90 \%$ of subjects followed online school classes and $83 \%$ also received indications from their Sports Associations about physical home-exercises and other forms of guided distance learning. Results from PACES showed that subjects liked the home physical activities with a mean value of $65.2 \pm 11.8$ with higher values from those who received online support from their regular instructors; moreover, higher values from PACES were obtained by middle school children respect to primary school children and high school adolescents. Despite the mandatory confinement, a positive feedback regarding the enjoyment was reported by children and adolescents for the home distance modality.

Keywords: Physical activities; Sport activities; Enjoyment; PACES; Home physical education; Distance learning.

Cite this article as:

Bonavolontà, V., Cataldi, S., Maci, D., \& Fischetti, F. (2020). Physical activities and enjoyment during the lockdown: Effect of home-based supervised training among children and adolescents. Journal of Human Sport and Exercise, 15(4proc), S1338-S1343. doi:https://doi.org/10.14198/ihse.2020.15.Proc4.31

Corresponding author. School of Medicine: Department of Basic Medical Sciences, Neuroscience and Sense Organs. University of Study of Bari "Aldo Moro", Lungomare Starita 1/b, 70132, Bari. Italy. https://orcid.org/0000-0002-5929-4766

E-mail: stefania.cataldi@uniba.it

Abstract submitted to: Spring Conferences of Sports Science. Costa Blanca Sports Science Events, 19-20 June 2020. Alicante, Spain.

JOURNAL OF HUMAN SPORT \& EXERCISE ISSN 1988-5202

(c) Faculty of Education. University of Alicante

doi:10.14198/jhse.2020.15.Proc4.31
\end{abstract}

S1338 $2020 \mid$ Proc4 | VOLUME 15

(C) 2020 University of Alicante 


\section{INTRODUCTION}

Fun and enjoyment are among the main components why individuals engage in physical and sports activities (PSA) at all ages, while the lack of enjoyment frequently leads to occasional participation or eventually, to dropout (Carraro et al., 2012).

From a general point of view, enjoyment plays an important role in the process of learning and helps children to think more deeply, retain information, and develop new knowledge (Hernik and Jaworska, 2018). Enjoyment is both a predictor and outcome of physical activity participation (Mullen et al., 2011) and it is considered a relevant component during PSA, necessary in joining and keeping the adherence to these activities (Carraro et al., 2008) as well as the personal motivation to follow up a healthy lifestyle (Pignato et al. 2019). Enjoyment of physical activities (PA) was the only consistent predictor of PA levels for boys and girls (Moore et al., 2009) among a great number of psychological and environmental variables. Enjoyment has also been related to motor ability in children: children who enjoy physical activity are 1.8-2.5 times more likely to be above the national average of motor ability compared with children who do not (Kakimura et al., 2019). Recently, Dębska et al. (2019) reported high levels of enjoyment also during immersive virtual gaming suggesting, concluding that it can be an effective strategy to increase the adherence in health-oriented PSA.

During the month of May 2020, Italy was the first European country to adopt unprecedented strong measures in restricting individual mobility and in promoting social distancing in order to interrupt the SARS-CoV-2 virus transmission and to contain the consequent spreading of COVID-19 which has evolved from epidemic to pandemic.

The COVID-19 pandemic has restricted physical activity (PA) in people of all ages (Shahidi et al., 2020), and the imposed rules of social distancing reduced the possibility to participate in formal organized and structured activities, especially for adolescent boys (Sekulic et al., 2020). In addition, as a result of school closure, many children are less active and they are unlikely to reach the 60 min of physical activity suggested by WHO and will suffer from the lack of social assistance provided by the school environment (Wang et al., 2020; Van Lancker et al., 2020). Maugeri and colleagues (2020) demonstrated that quarantine in Italy has induced a significant reduction of total weekly physical activity energy expenditure in all age group, especially in men, and that this reduction negatively affects the psychological well-being.

Hammami et al. (2020) proposed that implementing an adapted physical training program at home during the period of the pandemic would decrease the negative physiological and psychological impact of sedentary behaviours.

Anyway, to date, no studies have evaluated the level of enjoyment induced by the several home-based PSA programs proposed by private clubs and local sports associations during the pandemic outbreak.

Therefore, aim of this study was to assess the level of enjoyment of a home-based training in children and adolescents during the lockdown home confinement.

\section{METHODS}

140 among children and adolescents (60 aged $6-11$ and 80 aged $12-15,66 \%$ males and $34 \%$ females; $M$ age $=12.9 \pm 2.8$ years) recruited from 23 different Tennis Clubs of the six provinces of Apulian region, voluntarily participated in this study. Subjects were first asked if they were following online school lesson and, 
secondly, if they had received indications from their Tennis Clubs to continue their training at home during the lockdown.

To assess the levels of enjoyment it was used the Italian version of the Physical Activity Enjoyment Scale (PACES-It): it evaluates the level of enjoyment during physical and sports activities and it was validated in an Italian sample by Carraro et al. (2008) who concluded that PACES-IT is a reliable tool, thus supporting its use in the context of Italian Physical Education (PE). PACES is made up of 16 items scored on a scale ranging from 1 (disagree a lot) to 5 (agree a lot). PACES questionnaire beginning stem, which in its original form asks, "when I am physically active" was modified by asking subjects "During the lockdown, when I am physically active..." in order to better refer to the home confinement setting.

\section{RESULTS}

Results revealed that $90.7 \%$ of subjects followed online school didactics while $82.9 \%$ received support from Tennis Clubs. PACES questionnaire showed that subjects appreciated the home physical activities with a mean value of $65.2 \pm 11.8$ (female: 64.7 ; male: 65.45 ) with higher values from those who received online support and guidance from their regular instructors of Tennis Schools respect to their peers who did not (66.45 vs 59.17). Moreover, higher values from PACES were obtained by middle school children respect to primary school children and high school adolescents $(67.89,63.92$ and 63.42 respectively). Correlation coefficient was also calculated between PACES scores and support by the Tennis School $(p=.23)$.

\section{DISCUSSION AND CONCLUSIONS}

Previous studies highlighted the relation between physical activity and self-esteem (Russo et al., 2019) and that young students who practice regular and adequate physical and sports activities have shown a better body-size perception and a smaller body uneasiness (Fischetti et al., 2019). Thus, PSA not only are effective in improving physical fitness in children and adolescence (Fischetti et al., 2019), but affect also the cognitive, attentional (Gallotta et. al. 2011; 2020) and emotional area of the person.

Aim of this study was to assess the level of enjoyment during PSA in a sample of Italian children and adolescents in the Covid-19 home confinement.

Analysing the correlation coefficient between PACES and tennis school support, an interesting aspect emerged when comparing subjects who has had support from tennis schools and those who has not in relation to enjoyment levels. The group of those who received support shows significantly higher average enjoyment levels (65.45) than the group who had no indication (59.17). This indication suggests that, although it was possible to carry out activities at home even without being guided by instructors and trainers, this did not bring the same benefits on the state of pleasure as those who were followed by an expert, who was able to customize and adapt the games proposed, and above all to involve and motivate the children.

Moreover, interestingly, from a pedagogical point of view, PACES results revealed that pupils mostly enjoyed doing physical activity staying at home during the lockdown and did not consider it as a frustrating or annoying practice (Table 1). Table 1 shows that home-based physical activity had a high impact on enjoyment and motivation and that items representing negative feelings had low agreement by pupils. It is interesting to remark that subjects reported positive feedback on the home distance education modality even if, actually, they were not allowed to go to the usual location to play their favourite sport. 
The home-based training resulting in a blend of sport games situations and multilateral activities, could play a key role in the achievement of both increased motor skills (Sgrò et al., 2019; Fischetti et al., 2017) together with high level of enjoyment and thus, with higher motivation and participation. In relation to the latter point, Schembri et al. (2019) claimed that children with greater motor skills are more involved in physical and sports activity as they are able to apply their motor skills to various types of activities compared to children with a low motor skill level. Indeed, the relationships between basic motor skills, motor competences and fitness are keys to promote persistency of physically active lifestyles (Tortellia and Fumagalli, 2017). Moreover, Sgrò and colleagues (2020) recently reported that students involved in a tactical game model approach group experienced increased levels of enjoyment and perceived a motivational climate focused on improving their levels of task-related competences.

Thus, it can be concluded that the home-based training can be effective in maintaining the educational relationship between pupils and their teacher with high level of enjoyment by the former, even in an unprecedented scenario like the COVID-19 pandemic home confinement. Also, based on the data of the present study, the role of instructor appears to be crucial in motivating and guiding their pupils during PSA making them enjoyable and, possibly, increasing the possibility of maintaining the adherence to these activities.

Future studies should consider enjoyment as a fundamental component of PSA addressing also to unformal contexts especially in relation to the emergency measures due to the current pandemic situation and possibly involving the academic structure of physical and sport sciences courses (Raiola, 2020 a; b). Outdoor education could represent the ideal setting to increase the level of cognitive, emotional, social, fine motor skills during childhood (Monti et al., 2019) up to adulthood helping to foster the enjoyment/adherence relation.

Table 1. PACES Questionnaire report. Pupils were asked "During the lockdown, when I am physically active..."

\begin{tabular}{lccccc}
\hline Item & Disagree a lot & Disagree & I Am not sure & Agree & Agree a lot \\
\hline I enjoy it & 1 & 18 & 19 & 49 & 53 \\
I feel bored & 75 & 43 & 12 & 10 & 0 \\
I dislike it & 95 & 23 & 16 & 6 & 0 \\
I find it pleasureable & 4 & 18 & 18 & 50 & 50 \\
It's no fun at all & 91 & 29 & 11 & 8 & 1 \\
It gives me energy & 7 & 12 & 20 & 42 & 59 \\
It makes me sad & 113 & 12 & 11 & 4 & 0 \\
It's very pleasant & 6 & 22 & 15 & 55 & 42 \\
My body feels good & 3 & 16 & 15 & 47 & 59 \\
I get something out of it & 10 & 18 & 22 & 43 & 47 \\
It's very exciting & 16 & 20 & 31 & 44 & 29 \\
It frustrates me & 99 & 26 & 11 & 4 & 0 \\
It's not at all interesting & 104 & 17 & 14 & 4 & 1 \\
It gives a strong feelings of success & 16 & 23 & 31 & 34 & 36 \\
It feels good & 3 & 17 & 18 & 36 & 66 \\
I feel as though I would rather be & 75 & 33 & 15 & 9 & 8 \\
doing something else & & & & & \\
\hline
\end{tabular}




\section{REFERENCES}

Carraro, A., Young, M. C., \& Robazza, C. (2008). A contribution to the validation of the physical activity enjoyment scale in an Italian sample. Soc Behav Pers: int j, 36(7), 911-918. https://doi.org/10.2224/sbp.2008.36.7.911

Carraro, A. (2012). Valutare il piacere nelle attività motorie: il PACES-It. It J Ed Res, 259-265.

Dębska, M., Polechoński, J., Mynarski, A., \& Polechoński, P. (2019). Enjoyment and Intensity of Physical Activity in Immersive Virtual Reality Performed on Innovative Training Devices in Compliance with Recommendations for Health. IJERPH, 16(19), 3673. https://doi.org/10.3390/ijerph16193673

Fischetti, F., Greco, G. (2017). Multilateral methods in Physical Education improve physical capacity and motor skills performance of the youth. JPES, 17(3), 2160-2168.

Fischetti, F., Latino, F., Cataldi, S., \& Greco, G. (2019). Gender Differences in Body Image Dissatisfaction: The Role of Physical Education and Sport. JHSE. p.1-10. https://doi.org/10.14198/ihse.2020.152.01

Fischetti, F., Cataldi, S., Greco, G. (2019) A combined plyometric and resistance training program improves fitness performance in 12 to 14-years-old boys, Sport Sci Health, 15 (3), pp. 615-621. https://doi.org/10.1007/s11332-019-00560-2

Gallotta MC, Guidetti L, Franciosi E, Emerenziani GP, Bonavolontà V, and Baldari C (2011). Effects of varying type of exertion on children's attention capacity. Med Sci Sports Exerc. Mar;44(3):550. https://doi.org/10.1249/MSS.0b013e3182305552

Gallotta M. C., Bonavolontà V., Zimatore G., lazzoni S., Guidetti L., Baldari C (2020). Effects of Open (Racket) and Closed (Running) Skill Sports Practice on Children's Attentional Performance. TOSSJ, 13.

Hammami, A., Harrabi, B., Mohr, M., \& Krustrup, P. (2020). Physical activity and coronavirus disease 2019 (COVID-19): specific recommendations for home-based physical training. Managing Sport and Leisure, 1-6. https://doi.org/10.1080/23750472.2020.1757494

Hernik, J., \& Jaworska, E. (2018). The effect of enjoyment on learning. In INTED2018 proceedings (5-7 March) (pp. 508-514). https://doi.org/10.21125/inted.2018.1087

Kamimura, A., Kawata, Y., Izutsu, S., Shibata, N., \& Hirosawa, M. (2018). The Impact of Physical Activity Enjoyment on Motor Ability. In Congress of the International Ergonomics Association (pp. 639-645). Springer, Cham. https://doi.org/10.1007/978-3-319-96089-0_70

Maugeri, G., Castrogiovanni, P., Battaglia, G., Pippi, R., D'Agata, V., Palma, A., ... \& Musumeci, G. (2020). The impact of physical activity on psychological health during Covid-19 pandemic in Italy. Heliyon, 6(6), e04315. https://doi.org/10.1016/j.heliyon.2020.e04315

Monti, F., Farné, R., Crudeli, F., Agostini, F., Minelli, M., Ceciliani, A. (2019) The role of Outdoor Education in child development in Italian nursery schools, Early Child Devel Care, 189 (6), pp. 867882. https://doi.org/10.1080/03004430.2017.1345896

Moore, Justin B., Yin, Zenong, Hanes, John, Duda, Joan, Gutin, Bernard and Barbeau, Paule. (2009) Measuring Enjoyment of Physical Activity in Children: Validation of the Physical Activity Enjoyment Scale. J Appl Sport Psychol, 21: 1, S116 - S129. https://doi.org/10.1080/10413200802593612

Mullen, S. P., Olson, E. A., Phillips, S. M., Szabo, A. N., Wójcicki, T. R., Mailey, E. L., ... \& McAuley, E. (2011). Measuring enjoyment of physical activity in older adults: invariance of the physical activity enjoyment scale (paces) across groups and time. Int J Behav Nutr Phys Act, 8(1), 103. https://doi.org/10.1186/1479-5868-8-103

Pignato, S., Bonomo, R., Coppola, R., \& Casolo, F. (2019). An empirical study for assessing the level of enjoinment in an Italian primary school. JHSE, 14(4proc), S1017- S1021. https://doi.org/10.14198/ihse.2019.14.Proc4.63 
Raiola, G. (2020). The Movement and Sport Science in Italy towards the European Research Council, Physical Culture and Sport, Studies and Research, 86 (1), pp. 37-48. https://doi.org/10.2478/pcssr2020-0011

Raiola, G. (2020) Proposal of rearrangement of physical training and sport sciences methodology academic disciplines in italian university body. Sport Scie, 14 (1), pp. 43-47.

Russo, G., Nigro, F., Raiola, G., Ceciliani, A. (2019) Self-esteem in physically active middle school students, JPES, 19, pp. 1984-1988

Schembri, R., Quinto, A., Aiello, F., Pignato, S., \& Sgrò, F. (2019). The relationship between the practice of physical activity and sport and the level of motor competence in primary school children. JPES, 19, 1994-1998.

Sekulic, D., Blazevic, M., Gilic, B., Kvesic, I., \& Zenic, N. (2020). Prospective Analysis of Levels and Correlates of Physical Activity During COVID-19 Pandemic and Imposed Rules of Social Distancing; Gender Specific Study Among Adolescents from Southern Croatia. Sustainability, 12(10), 4072. https://doi.org/10.3390/su12104072

Shahidi, S. H., Stewart Williams, J., \& Hassani, F. (2020). Physical activity during COVID-19 quarantine. Acta Paediatr. https://doi.org/10.1111/apa.15420

Sgrò, F., Quinto, A., Platania, F., \& Lipoma, M. (2019). Assessing the impact of a physical education project based on sports-games approach on the actual motor competence of primary school children. JPES. 19(Supplement Issue 3), 781-786.

Sgrô, F., Barca, M., Schembri, R., \& Lipoma, M. (2020). Assessing the effect of different teaching strategies on students' affective learning outcomes during volleyball lessons. JPES, 20, 2136-2142.

Tortella, P., \& Fumagalli, G. (2017). The effect of teaching methodologies in promoting physical and cognitive development in children. Physical Activity and Educational Achievement: Insights from Exercise Neuroscience, 297, 303-316. https://doi.org/10.4324/9781315305790-17

Van Lancker, W., \& Parolin, Z.: COVID-19, school closures, and child poverty: a social crisis in the making. Lancet Public Health, 5(5), e243-e244 (2020). https://doi.org/10.1016/S24682667(20)30084-0

Wang, G., Zhang, Y., Zhao, J., Zhang, J., Jiang, F. (2020). Mitigate the effects of home confinement on children during the COVID-19 outbreak. Lancet, 395(10228), 945-947. https://doi.org/10.1016/S0140-6736(20)30547-X 